Original paper

\title{
The association between juvenile autoimmune hepatitis and HLA-DRB1 alleles: Iraqi tertiary center experience
}

\author{
Mohammad Fadhil Ibraheem, Shaymaa Jamal Ahmed \\ College of Medicine, University of Baghdad, Iraq
}

\begin{abstract}
Aim of the study: To highlight the impact of the human leukocyte antigen (HLA) allele on susceptibility and prevention of autoimmune hepatitis (AlH) in Iraqi children.

Material and methods: We conducted a prospective study from children attending the Gastroenterology and Hepatology Clinic of Children's Welfare Teaching Hospital over five years from the first of September 2015 to the thirty-first of August 2020. It included 19 patients with $\mathrm{AlH}$; their age (at time of diagnosis) ranged between 3 and 16 years, with a female predominance of $78.9 \%$. The diagnosis was made by clinical, serological, and histological features. In addition, 20 age- and sex-matched unrelated subjects of the same ethnic background were selected randomly from healthy individuals undergoing checkup as controls.

Results: 19 patients diagnosed with AlH were included in this study, and 20 age- and sex-matched healthy controls, with a female predominance of $78.9 \%$. The commonest autoantibodies found were smooth muscle antibody (SMA) in $13(68.4 \%)$, antinuclear antibody (ANA) in 11 (57.9\%). In AlH type 1, PCR showed higher frequencies among patients with HLA-DRB1*03, HLA-DRB1 ${ }^{*} 04, \mathrm{HLA}-\mathrm{DRB} 1{ }^{*} 13$ alleles in patients with AlH; moreover DRB $1{ }^{*} 11$ and DRB $1 * 15$ were less frequent than in the control group. Frequency of HLA-DRB $1{ }^{*} 04$ was $28 \%$ and HLA-DRB $1{ }^{*} 13$ was $20 \%$ in AlH type 2 patients; HLA-DRB $1{ }^{*} 13$ and HLA-DRB5 showed frequency of $25 \%$ for both and HLA-DRB4 frequency was $18.7 \%$.

Conclusions: HLA-DRB $1 * 13, \mathrm{DRB} 1 * 04$, and DRB $1 * 03$ are susceptibility alleles for the development of AlH type 1, while HLA-DRB1*13, HLA-DRB4 and DRB5 are susceptibility alleles for the development of AlH type 2 in Iraqi children.
\end{abstract}

Key words: clinical features, HLA, autoimmune hepatitis, Iraqi children.

Address for correspondence:

Prof. Mohammad Fadhil Ibraheem, College of Medicine, University of Baghdad, Iraq, e-mail: mohammad68alqaisi@gmail.com

\section{Introduction}

Juvenile autoimmune hepatitis (JAIH) is a multifactorial polygenetic disease characterized by a progressive inflammatory liver disease, with active liver damage manifested by elevated liver associated serum autoantibodies, serum amino transaminase concentrations, and/or hypergammaglobulinemia and extra-hepatic manifestations. It was first reported in the early 1950s by the Swedish physician Jan Waldenström, who described a disease of young women. It occurs worldwide, affect- ing mainly young girls, from infancy to late adolescence $[1,2]$. The prevalence of AIH is unknown [3].

The etiology of autoimmune hepatitis is undetermined; it is postulated that a combination of environmental triggers, with failure of immune tolerance mechanisms, and a genetic predisposition participate in induction of a $\mathrm{T}$ cell-mediated immune attack on liver antigens, resulting in progressive necroinflammatory and fibrotic process in the liver $[4,5]$.

The susceptibility to AIH is imparted by genes of the human leukocyte antigen (HLA) region located on the 
short arm of chromosome 6, especially those encoding DRB1 alleles, which are involved in the presentation of antigenic peptides to $\mathrm{T}$ cells, and therefore participate in the initiation of an adaptive immune response [6].

Autoimmune hepatitis is divided into two main types according to the autoantibody profile: type 1, positive for antinuclear (ANA) and/or anti-smooth muscle (SMA) autoantibodies; and type 2, positive for antiliver kidney microsomal type 1 (anti-LKM1) and/or anti-liver cytosol type 1 (anti-LC-1) autoantibodies.

Both types of AIH may be diagnosed in childhood, are more common in females (75\% preponderance), and may be associated with an extrahepatic autoimmune disease such as Graves' disease, arthritis, inflammatory bowel disease (IBD), glomerulonephritis, or insulin-dependent diabetes $[7,8]$.

\section{Material and methods}

A prospective study was conducted on children attending the Gastroenterology and Hepatology Clinic of Children Welfare Teaching Hospital, Baghdad, Iraq over a period of five years from the first of September 2015 to the thirty-first of August 2020.

A total of 19 patients with AIH were included in this study, their age (at time of diagnosis) ranged between 3 and 16 years, and the mean age was 9.3 years, with female predominance of $78.9 \%$. The diagnosis of AIH was made by clinical, serological, and histological features. In addition, 20 age- and sex-matched unrelated subjects of the same ethnic background were selected randomly from healthy individuals undergoing checkup as controls.

Written consent was obtained from all participants. Moreover, the study was approved by the Ethical Scientific Committee of Children's Welfare Teaching Hospital and was carried out according to the guidelines of the Helsinki Declaration [9].

Fourteen patients presented with AIH type I and five patients with AIH type II. All the patients with hepatitis due to other causes such as viral hepatitis B

Table 1. Clinico-epidemiological features at presentation

\begin{tabular}{lc}
\hline Variables & Number of patients \\
\hline Age (years), median (range) & $9.3(3-16)$ \\
\hline Gender & \\
\hline Female, $n(\%)$ & $15(78.9)$ \\
\hline Male, $n(\%)$ & $4(21.1)$ \\
\hline Type AlH & \\
\hline Type $1, n(\%)$ & $14(73.68)$ \\
\hline Type 2, $n(\%)$ & $5(26.32)$ \\
\hline
\end{tabular}

and $\mathrm{C}$, Epstein-Barr virus and cytomegalovirus and metabolic disorders were excluded by appropriate serologic tests. A precise clinical history excluding drug consumption or other toxic materials was taken.

The confirmation of the diagnosis was based onEASL Clinical Practice Guidelines: Autoimmune hepatitis, Journal of Hepatology 2015 [10], and the ESPGHAN Hepatology Committee Position Statement 2018 [11]; 19 patients with definitive or probable diagnosis were included.

The genetic study of the HLA-DRB allele was performed in the genetic laboratory in the Biology Department, College of Medicine, University of Baghdad by an expert team.

$1.5 \mathrm{ml}$ of venous blood was drawn from the patients in sterile EDTA tubes and DNA was extracted using a kit (Geneaid, USA). NanoDrop used to measure the concentration and purity of DNA. The concentration range was $1.84-1.98 \mathrm{mg} / \mathrm{ml}$ and the purity range was 1.56-1.84. Products were separated by electrophoresis on $2 \%$ agarose and visualized with ethidium bromide and UV transillumination. All DNA typings were run according to manufacturer instructions.

The frequencies of the HLA-DRB allelic groups were determined by direct counting and compared between patient and control groups using the chi-square test with Yates correction. The patients were divided into AIH type 1 and AIH type 2. Data were expressed as mean \pm standard deviation (SD) for quantitative measurements and both number and percentage of subjects were included. The statistical analysis was done using the SPSS version 20.0 software for data entry and analysis; the results were expressed as mean \pm SD. The data were statistically analyzed using the standard $\chi^{2}$ test to determine the associations between two categorical variables. Yates correction formula and Fisher's exact test were applied for the $\chi^{2}$ test whenever it was needed. $P$-values less than 0.05 were considered as statistically significant.

\section{Results}

Among 19 patients, 15 were female (78.9\%), and 4 were male $(21.1 \%)$; their age (at time of diagnosis) ranged between 3 and 16 years (mean: 9.3, SD \pm 3.49 ) at the time of admission.

About 3/4 of the patients (14 patients) were diagnosed with type $1 \mathrm{AIH}$ (73.68\%), and 5 patients were diagnosed with type $2 \mathrm{AIH}(26.32 \%)$ as shown in Table 1.

Among the 19 patients it was found that the autoimmune markers present were SMA 13 (68.4\%), ANA 11 (57.9\%), p-ANCA 4 (21\%), anti-LKM 3 (15.7\%), soluble liver antigen (SLA) 2 (10.5\%), as shown in Table 2. 
Table 2. Prevalence of autoimmune markers among AlH patients

\begin{tabular}{lc}
\hline Autoimmune markers & Number (\%) \\
\hline Smooth muscle antibody (SMA) & $13(68.4)$ \\
\hline Antinuclear antibody (ANA) & $11(57.9)$ \\
\hline Perinuclear anti-neutrophil & $4(21)$ \\
\hline Cytoplasmic antibodies (p-ANCA) & $3(15.7)$ \\
Anti-liver kidney microsomal (anti-LKM) & \\
\hline Soluble liver antigen (SLA) & $2(10.5)$ \\
\hline
\end{tabular}

At the time of presentation all the patients showed remarkably increased levels of alanine aminotransferase (ALT) (mean $375.6 \mathrm{U} / \mathrm{l}, \mathrm{SD} 229.5$ ) and aspartate aminotransferase (AST) (mean $439 \mathrm{U} / \mathrm{l}, \mathrm{SD} 254.5$ ), and with a tremendous rise of serum IgG (mean $3246 \mathrm{~g} / \mathrm{dl}$, SD 1121), total serum bilirubin (TSB) and direct bilirubin $(7.34,5.39$ respectively), prothrombin time (PT) (19), total protein and albumin (6.5, 3.9 respectively), as shown in Table 3.

Regarding allele frequencies compared between AIH type 1 patients and the healthy control group, higher frequencies of $\mathrm{DRB}^{\star} 03(14.2 \%$ vs. $5.2 \%$, $p=0.01)$ and $\mathrm{DRB}^{\star} 4(17.1 \%$ vs. $10.5 \%, p=0.01)$ were found in AIH1 patients than in controls and in DRB $1^{\star} 13(20 \%$ vs. $8.7 \%, p=0.002)$. However, the frequencies of $\mathrm{DRB} 1^{\star} 11$ and $\mathrm{DRB1} 1^{\star} 15(8.5 \%$ vs. $21 \%$,
Table 3. Biochemical findings in AlH

\begin{tabular}{lcc}
\hline Variable & Mean (range) & SD \\
\hline AST (IU/l) & $439(123-985)$ & 254.5 \\
\hline ALT (IU/l) & $375(106-834)$ & 229.5 \\
\hline ALP (IU/l) & $284(134-796)$ & 171 \\
\hline Total bilirubin (mg/dl) & $7.34(2.8-13.7)$ & 3.37 \\
\hline Direct bilirubin (mg/dl) & $5.39(1.1-8.9)$ & 2.48 \\
\hline PT (s) & $19(13-35)$ & 6.72 \\
\hline Total protein (g/dl) & $6.5(5.3-8.1)$ & 0.86 \\
\hline Albumin & $3.9(2.2-4.8)$ & 0.64 \\
\hline IgG (mg/dl) & $3246(1910-5700)$ & 1121 \\
\hline IgM (mg/dl) & $136.5(35-240)$ & 56.6 \\
\hline IgA (mg/dl) & $130(30-250)$ & 70.2 \\
\hline
\end{tabular}

AST - aspartate aminotransferase, ALT - alanine aminotransferase, ALP - alkaline phosphatase, $P T$ - prothrombin time

$p=0.01 ; 2.8 \%$ vs. $21 \%, p=0.0001)$, respectively, were vice versa.

In DRB3 frequency was $34.2 \%$ vs. $22.8 \%, p=0.0001$, and in DRB4 $28.5 \%$ vs. $14 \%, p=0.0001$.

Regarding the comparison between AIH type 2 patients and the healthy control group we found in $\mathrm{DRB}{ }^{\star} 13$ $25 \%$ vs. $8.7 \%, p=0.002$, and in DRB4 and DRB5 $18.7 \%$ vs. $14 \%, p=0.04$ and $25 \%$ vs. $8.7 \%, p=0.002$, respectively, as shown in Table 4.

Table 4. Allele frequencies among Iraqi children AlH type 1, AlH type 2 and healthy controls

\begin{tabular}{|c|c|c|c|c|c|c|c|}
\hline HLA & $\begin{array}{l}\text { Healthy controls } \\
\qquad(n=50) \\
(57 \text { alleles })\end{array}$ & $\begin{array}{c}\text { AlH1 }(n=14) \\
\text { (35 alleles) }\end{array}$ & Odd ratio & $p$-value & $\begin{array}{c}\text { AlH2 }(n=5) \\
\text { (16 alleles) }\end{array}$ & Odd ratio & $p$-value \\
\hline \multicolumn{8}{|l|}{ DRB1* } \\
\hline $\mathrm{DRB} 1{ }^{*} 01$ & $2(3.5 \%)$ & $2(5.7 \%)$ & $1.6(0.3-11.7)$ & 0.2 & 0 & 0 & \\
\hline $\mathrm{DRB} 1{ }^{*} 03$ & $3(5.2 \%)$ & $5(14.2 \%)$ & $3.8(1.7-8.6)$ & 0.01 & $1(6.2 \%)$ & $3.1(0.4-22.1)$ & 0.3 \\
\hline $\mathrm{DRB} 1{ }^{*} 04$ & $6(10.5 \%)$ & $6(17.1 \%)$ & $3.2(1.3-7.6)$ & 0.01 & 0 & 0 & \\
\hline $\mathrm{DRB} 1{ }^{*} 07$ & $7(12.2 \%)$ & $4(11.4 \%)$ & $1.9(0.7-5)$ & 0.1 & $5(31.2 \%)$ & 0 & \\
\hline $\mathrm{DRB} 1$ *09 & $2(3.5 \%)$ & $2(5.7 \%)$ & $2.5(0.8-7.5)$ & 0.2 & 0 & 0 & \\
\hline $\mathrm{DRB} 1 * 10$ & $3(5.2 \%)$ & $1(2.8 \%)$ & $1.1(0.1-6.7)$ & 0.6 & $1(6.2 \%)$ & $3.1(0.4-22.1)$ & 0.3 \\
\hline DRB1*11 & $12(21 \%)$ & $3(8.5 \%)$ & $0.8(0.2-2.7)$ & 0.5 & $3(18.7 \%)$ & $4(0.7-21)$ & 0.1 \\
\hline DRB1*13 & $5(8.7 \%)$ & $7(20 \%)$ & $4.3(1.8-10)$ & 0.002 & $4(25 \%)$ & $20.4(2.5-166)$ & 0.002 \\
\hline $\mathrm{DRB} 1 * 14$ & $3(5.2 \%)$ & $2(5.7 \%)$ & $1.9(0.6-6.4)$ & 0.2 & $1(6.2 \%)$ & $3.1(0.4-22.1)$ & 0.3 \\
\hline $\mathrm{DRB} 1 * 15$ & $12(21 \%)$ & $1(2.8 \%)$ & $0.4(0.07-3.7)$ & 0.3 & $1(6.2 \%)$ & $1.2(0.1-10)$ & 0.6 \\
\hline $\mathrm{DRB} 1 * 16$ & $2(3.5 \%)$ & $2(5.7 \%)$ & $1.6(0.4-55)$ & 0.3 & 0 & 0 & \\
\hline \multicolumn{8}{|c|}{ DRB3*/4*/5* } \\
\hline DRB3 & $13(22.8 \%)$ & $12(34.2 \%)$ & $9.3(2.2-38)$ & 0.0001 & $5(31.2 \%)$ & 0 & \\
\hline DRB4 & $8(14 \%)$ & $10(28.5 \%)$ & $6.3(2.2-17)$ & 0.0001 & $3(18.7 \%)$ & $6(1.1-31)$ & 0.04 \\
\hline DRB5 & $5(8.7 \%)$ & $4(11.4 \%)$ & $2.4(0.9-6.1)$ & 0.09 & $4(25 \%)$ & $20(2.5-162)$ & 0.002 \\
\hline
\end{tabular}

Values of $p<0.05$ (significant) are shown in bold font. 


\section{Discussion}

The median age of the affected children was 9.3, which was in concordance with other studies [12-14]. Regarding gender preponderance, it was found that females were much more highly affected $(78.9 \%)$ than males, and these results are in line with other studies all over the world [15-17].

However, Miyake et al. in Japan reported that males and females had the same frequency of symptomatic simultaneous autoimmune diseases [18]. This incongruity with the Japanese study may be explained by genetic background, ethnic diversity, and environmental factors. In this study we recorded that AIH type 1 was present in $(73.68 \%)$ of the cases while AIH type 2 was present in $26.32 \%$ and that was comparable with other studies in different parts of the globe $[16,19-22]$. We found in this study that ANA was positive in $57.9 \%$, SMA was positive in $68.4 \%$, anti-LKM was positive in $15.7 \%$, SLA in $10.5 \%$, and pANCA was positive in $21 \%$.

In other studies, positive ANA was in the range 16.7-67\%, positive SMA was in the range $24-86.7 \%$, anti-LKM was positive in $16.7-30 \%$, SLA was in the range $5.5-16.6 \%$, and for pANCA it was $16-30 \%$ [13, $16,19,22,23]$.

We found that among our studied patients with $\mathrm{AIH}, \mathrm{DRB}^{\star} 13$ (frequency of $20 \%$ ) was the primary susceptibility allele in Iraqi children, followed by $\mathrm{DRB} 1^{\star} 04(17.1 \%)$ as the second susceptibility allele, and then HLA-DRB1*03 (14.2\%) (Fig. 1).

In accordance with other studies in different parts of the globe, HLA-DRB1 ${ }^{\star} 13$ was reported as a major susceptibility allele for the occurrence of AIH as in Egypt by Elfaramawy et al., who found that the most predominant HLA alleles among AIH children were HLA-DRB $1^{\star} 13$ (36\%), HLA-DRB1 ${ }^{\star} 04$ (18\%) and HLA-DRB ${ }^{\star} 03(14 \%)$, and the frequency of HLA$\mathrm{DRB}^{\star} 13$ was obviously higher in the patient group compared to the control group [24].
In Brazilian patients, Bittencourt et al. reported different HLA antigens (HLA-DRB1 ${ }^{\star} 13 / \mathrm{DRB} 3 / \mathrm{DQB} 1^{\star} 06$ haplotype confers susceptibility to AIH type 1 and HLA-DQB1*07/DRB4/DQB1 ${ }^{\star} 02$ haplotype confers susceptibility to AIH type 2) [25].

In Argentina, Fainboim et al. also found that HLA$\mathrm{DRB}^{\star} 13$ is a risk factor for type $1 \mathrm{AIH}$, and HLA$\mathrm{DRB}^{\star} 03$ and $\mathrm{DRB} 1^{\star} 04$ are independent risk factors for the disease in white North Americans [26].

In Pakistan, Hassan et al. found that HLA-DRB1 ${ }^{\star} 13$ and HLA-DRB1 ${ }^{\star} 14$ were more prevalent among $\mathrm{AIH}$ children [27].

It was found that the $\mathrm{DRB}^{\star} 13$ allele is more common in the white population, but with a low frequency in African and in the Far East population [28].

In this study we found significant associations between AIH and HLA-DRB3 (34.2\%), HLA-DRB4 (28.5\%) and HLA DRB5 (11.4\%) in comparison to the control group.

The prevalence of HLA-DR3 was increased in European patients [27], and these alleles are more common in AIH Caucasian patients [29].

DR3 in the Japanese population was rarely found and AIH was associated with DR4, especially in the older age group [30].

In our study the prevalence of $\mathrm{HLA}_{-\mathrm{DRB}}{ }^{\star} 13$, in addition to HLA-DRB4 and HLA-DRB5, was obviously higher among patients with AIH type 2 in comparison to the control group, which is in agreement with other studies [22, 24, 29, 30].

In contrast, HLA-DRB $1^{\star} 11$ and $\mathrm{HLA}-\mathrm{DRB} 1^{\star} 15$ had lower frequencies in $\mathrm{AIH}$ patients in comparison to the control group. These alleles can play a role as protective and preventive factors in development of AIH type 1 in Iraqi children.

Furthermore, our data showed that the frequency of HLA-DRB1*13, in addition to HLA-DRB4 and HLA-DRB5, was obviously higher among patients with AIH type 2 in comparison to the control group.
A

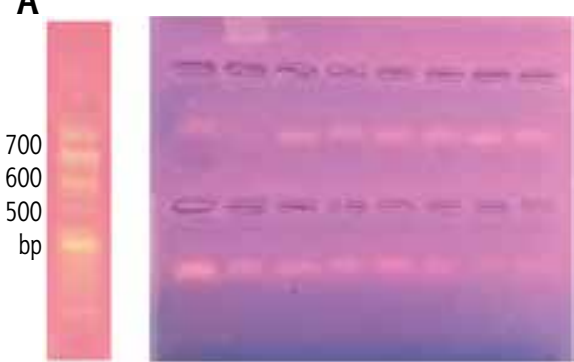

HLA-DRB $1 * 13$
B

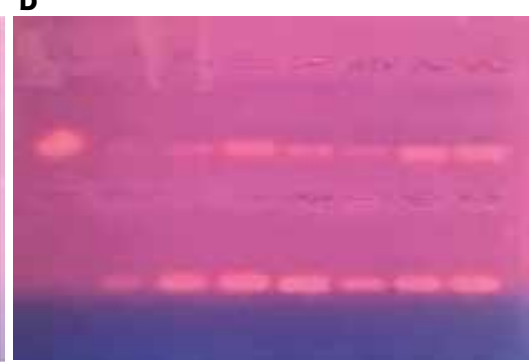

HLA-DRB 1 *04

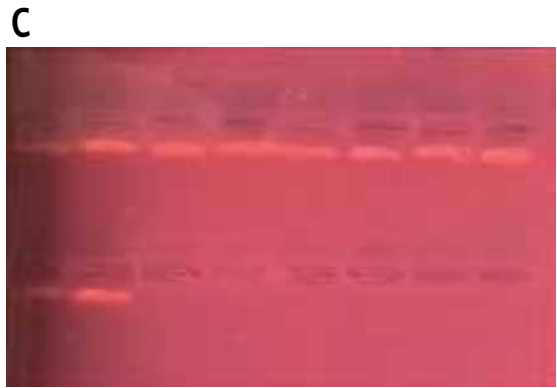

HLA-DRB1 *07 and HLA-DRB1 *03

Fig. 1. PCR of Iraqi children AlH 


\section{Conclusions}

HLA-DRB1 $1^{\star} 13, \mathrm{DRB} 1^{\star} 04$, and $\mathrm{DRB} 1^{\star} 03$ are susceptibility alleles for the development of AIH type 1, while HLA-DRB1*13, HLA-DRB4 and DRB5 are susceptibility allele for the development of AIH type 2 . Furthermore, HLA-DRB $1^{\star} 11$ and HLA-DRB1 ${ }^{\star} 15$ had lower frequency in AIH patients; these alleles can play protective and preventive roles in Iraqi children.

\section{Acknowledgements}

We are grateful to all subjects and investigators who participated in this study, we are thankful greatly appreciate the cooperation of all the patients who participated in this project.

\section{Disclosure}

The authors declare no conflict of interest.

\section{References}

1. Maggiore G, Nastasio S, Sciveres M. Juvenile autoimmune hepatitis: Spectrum of the disease. World J Hepatol 2014; 6: 464-476.

2. Mackay IR. Historical reflections on autoimmune hepatitis. World J Gastroenterol 2008; 14: 3292-3300.

3. Mieli-Vergani G, Vergani D. Autoimmune hepatitis. Nat Rev Gastroenterol Hepatol 2011; 8: 320-329.

4. Vergani D, Choudhuri K, Bogdanos DP, et al. Pathogenesis of autoimmune hepatitis. Clin Liver Dis 2002; 6: 727-737.

5. Czaja AJ. Autoimmune hepatitis. Part A: pathogenesis. Expert Rev Gastroenterol Hepatol 2007; 1: 113-128.

6. Liberal R, Longhi MS, Mieli-Vergani G, et al. Pathogenesis of autoimmune hepatitis. Best Pract Res Clin Gastroenterol 2011; 25: 653-664.

7. Czaja AJ, dos Santos RM, Porto A, et al. Immune phenotype of chronic liver disease. Dig Dis Sci 1998; 43: 2149-2155.

8. Gregorio GV, Portmann B, Karani J, et al. Autoimmune hepatitis/sclerosing cholangitis overlap syndrome in childhood: a 16year prospective study. Hepatology 2001; 33: 544-553.

9. World Medical Association. Declaration of Helsinki-Ethical Principles for Medical Research Involving Human Subjects, the 59th WMA General Assembly, Seoul, South Korea 2008.

10. EASL Clinical Practice Guidelines: Autoimmune hepatitis. J Hepatol 2015; 63: 971-1004.

11. Vergani G Vergani M, Baumann U, et al. Diagnosis and management of pediatric autoimmune liver disease: ESPGHAN Hepatology Committee Position Statement. J Pediatr Gastroenterol Nutr 2018; 66: 345-360.

12. Rafeey M, Kianrad M, Hasni A. Autoimmune hepatitis in Iranian children. Indian J Gastroenterol 2007; 26: 11-13.

13. Ferreira AR, Roquete ML, Penna FJ, et al. Autoimmune hepatitis in children and adolescents: clinical study, diagnosis and therapeutic response. J Pediatr (Rio J) 2002; 78: 309-314.

14. Dehghani SM, Haghighat M, Imanieh MH, et al. Autoimmune hepatitis in children: experiences in a tertiary center. Iran J Pediatr 2013; 23: 302-308.
15. Saadah O, Smith AL, Hardikar W. Outcome of autoimmune hepatitis in children, Long-term outcome of autoimmune hepatitis in children. J Gastroenterol Hepatol 2001; 16: 1297-1302.

16. El-Koofy N, Fahmy M, Aziz M, et al. Features of autoimmune hepatitis in Egyptian children. Med J Cairo Univ 2010; 78: 107112.

17. Yachha SK, Srivastava A, Chetri K, et al. Autoimmune liver disease in children. J Gastroenterol Hepatol 2001; 16: 674-677.

18. Miyake Y, Iwasaki Y, Sakaguchik, et al. Clinical features of Japanese male patients with type 1 autoimmune hepatitis. Aliment Pharmacol Ther 2006; 24: 519-523.

19. Güleç SG, Urgancı N, Demirel E, et al. Evaluation of patients with autoimmune hepatitis: eleven years of experience. Turk Arch Ped 2012; 47: 29-34

20. Farid E, Isa HM, Al Nasef M, et al. Childhood autoimmune hepatitis in Bahrain: a tertiary center experience. Iran J Immunol 2015; 12: 141-148.

21. Czaja AJ. Genetic factors affecting the occurrence, clinical phenotype, and outcome of autoimmune hepatitis. Clin Gastroenterol Hepatol 2008; 6: 379-388.

22. Baharlou R, Kashani AF, Faraji F, et al. HLA-DRB1 alleles of susceptibility and protection in Iranians with autoimmune hepatitis. Hum Immunol 2016; 77: 330-335.

23. Maggiore G, Nastasio S, Sciveres M. Juvenile autoimmune hepatitis: Spectrum of the disease. World J Hepatol 2014; 6: 464-476.

24. Elfaramawy A, Elhossiny RM, Abbas AA, et al. HLA-DRB1 as a risk factor in children with autoimmune hepatitis and its relation to hepatitis A infection. Ital J Pediatr 2010; 36: 73.

25. Bittencourt PL, Farias AQ, Porta G, et al. Frequency of concurrent autoimmune disorders in patients with autoimmune hepatitis effect of age, gender, and genetic background. J Clin Gastroenterol 2008; 42: 300-305.

26. Fainboim L, Velasco M, Marcos CY, et al. Protracted, but not acute, hepatitis A virus infection is strongly associated with HLA-DRB1 ${ }^{\star} 1301$, a marker for pediatric autoimmune hepatitis. Hepatology 2001; 33: 1512-1517.

27. Hassan N, Siddiqui AR, Abbas Z, et al. Clinical profile and HLA typing of autoimmune hepatitis from Pakistan. Hepat Mon 2013; 13: e13598.

28. Saito S, Yamada E, Inoko H, Ota M. Allele frequencies and haplotypic associations defined by allelic DNA typing at HLA class I and class II loci in the Japanese population. Tissue Antigens 2000; 56: 522-529.

29. Czaja AJ. Understanding the pathogenesis of autoimmune hepatitis. Am J Gastroenterol 2001; 96: 1224-1231.

30. Umemura T, Katsuyama Y, Yoshizawa K, et al. Human leukocyte antigen class II haplotypes affect clinical characteristics and progression of type 1 autoimmune hepatitis in Japan. PLoS One 2014; 9: e100565. 